\title{
Androgen Deprivation Therapy Induces Vitamin K Loss in Men with Prostate Cancer
}

\section{Hisashi Matsushima}

Department of Urology, Tokyo Metropolitan Police Hospital 4-22-1, Nakano, Nakano-Ku, Tokyo, Japan

*Corresponding author: Hisashi Matsushima, M.D., Ph.D., General Manager, Department of Urology, Tokyo Metropolitan Police Hospital 4-22-1, Nakano, Nakano-Ku, Tokyo 164-0001, Japan, Tel: +81-03-5343-5611; Fax: +81-03-5343-5612; E-mail: hmatsu53@me.com

Received date: July 01, 2017; Accepted date: July 20, 2017; Published date: July 27, 2017

Copyright: (c) 2017 Matsushima $\mathrm{H}$. This is an open-access article distributed under the terms of the Creative Commons Attribution License, which permits unrestricted use, distribution, and reproduction in any medium, provided the original author and source are credited.

\begin{abstract}
Bone strength is determined by bone mineral density (BMD) and bone quality. Bone fractures are serious adverse events in men receiving androgen deprivation therapy (ADT) for prostate cancer. Although it is established that ADT reduces $B M D$, it is unclear how $A D T$ alters bone quality. Vitamin $K$ is a bone quality marker which aids to carboxylates osteocalcin to form bone matrix. Serum undercarboxylated osteocalcin (UCOC) is accumulated in vitamin $\mathrm{K}$ deficiency, which is used as a surrogate for vitamin $\mathrm{K}$ status. As little is known as to the impact of ADT on serum ucOC, we investigated the changes of serum ucOC in PC patients during ADT. Fifty consecutive hormone naïve PC patients were enrolled. Serum ucOC, serum osteocalcin (OC), serum Nteloptide of type 1 collagen (NTx) and hip bone mineral density (BMD) were measured at baseline, 6 month and 12 months since the start of ADT. Serum ucOC levels at 6 and 12 months $(3.86 \pm 2.28$ and $4.32 \pm 1.76 \mathrm{ng} / \mathrm{ml})$ were significantly higher than those at baseline $(2.46 \pm 1.46 \mathrm{ng} / \mathrm{ml})$. Serum OC levels at 12 months $(7.82 \pm 2.65 \mathrm{ng} / \mathrm{ml})$ were significantly higher than those at baseline $(5.26 \pm 1.86 \mathrm{ng} / \mathrm{ml})$. Furthermore, the ratio of ucOC/OC at 1 year $(0.54 \pm 0.15)$ were significantly higher than at baseline $(0.42 \pm 0.18)$. Both serum NTx levels and hip BMDs at 6 and 12 months were also significantly higher than those at baseline. Our results first demonstrated that ADT induced vitamin $\mathrm{K}$ loss in men with prostate cancer. Further investigations are required to determine whether vitamin $\mathrm{K}$ supplement is useful to prevent bone fractures in men on ADT.
\end{abstract}

Keywords: Undercarboxylated osteocalcin; Androgen deprivation therapy; Prostate cancer; Vitamin K; Osteoporosis

\section{Introduction}

Androgen deprivation therapy (ADT) with gonadotropin-releasing hormone analogues combined with or without nonsteroidal antiandrogens is standard treatment for advanced prostate cancer. As this intervention results in significant improvement in survival, interest is now focused on the long-term adverse effects of ADT.

ADT reduces bone mineral density (BMD) in patients with prostate cancer, and this reduction can be demonstrated within 6 months of starting therapy [1]. Annual loss of BMD is about $2 \%-8 \%$ per year at the lumbar spine and $1.8 \%-6.5 \%$ at the hip [2]. Of men surviving at least 5 years after diagnosis of prostate cancer, $19.4 \%$ of those receiving ADT had a fracture, compared with $12.6 \%$ of those not receiving ADT [3].

As $\mathrm{ADT}$ increases serum and urinary markers of bone resorption, which are indicative of high osteoclast activity, osteoclast-targeted therapies are commonly used to reduce the risk for ADT-related osteoporosis and fractures [3-5]. These fractures cause substantial morbidity, and the mortality following hip fracture is greater in men than in women. A previous prospective study found the mortality ratio after hip fracture to be 3.2 for men and 2.2 for women [6]. Low BMD is a key predictor of primary osteoporotic fractures in both men and women [7].

Dual energy X-ray absorptiometry (DXA) is commonly used to measure BMD, although men may experience fractures at higher BMD than women. A recent study has shown that BMD measured by DXA alone resulted in the misdiagnosis of approximately $75 \%$ of patients with prostate cancer receiving ADT for 6 months or more [8].

Although DXA is the gold standard for evaluation and diagnosis of osteoporosis, other modalities for measuring bone mass, geometry, and architecture are under investigation. Undercarboxylated osteocalcin ( $\mathrm{ucOC}$ ), a sensitive marker of vitamin $\mathrm{K}$ status, is correlated with age $[9,10]$ and the risk of hip fracture in women [10]. The serum ucOC levels are also correlated with ultrasonic transmitted velocity in bone and are thought to be markers of bone quality [9].

Previous studies have shown that serum ucOC levels were negatively correlated with serum estradiol and increased in postmenopausal and oophorectomized women $[11,12]$. However, there have been no reports on changes in serum ucOC levels in men with prostate cancer receiving ADT.

In this study, we retrospectively examined the longitudinal changes in serum ucOC levels, bone turnover markers, and total hip BMD in men with prostate cancer during the course of ADT.

\section{Materials and Methods}

\section{Subjects}

This retrospective observational study consisted of 50 Japanese patients with non-metastatic prostate cancer who received ADT. Patients with previous bone fractures, a history of previous ADT or orthopedic surgery, renal dysfunction, anticoagulant or warfarin use, glucocorticoid use, or metabolic bone diseases were excluded from the study. ADT was performed using the combination of a luteinizing 
Page 2 of 6

hormone-releasing hormone agonist and a nonsteroidal antiandrogen bicalutamide. Serum total testosterone levels were measured at 3 months to confirm reduction to a castration level $(<50 \mathrm{ng} / \mathrm{dl})$. Monitoring was continued until the start of bone targeting therapy using bisphosphonates and/or vitamin K2.

\section{Biochemical measurements}

Serum levels of ucOC were measured using an electrochemiluminescence immunoassay (ECLIA) kit (Picolumi ucOC; Sanko Junyaku, Ibaraki, Japan) [13]. Serum total osteocalcin (OC) was measured with a BGP immunoradiometric assay kit (Mitsubishi Chemical Medience Corp., Tokyo, Japan), serum total testosterone with a Testone 111 ECLIA kit (Roche Diagnostics, USA), and serum free testosterone with a Coat-A-Count Free Testosterone kit (Siemens Medical Solution Diagnostics, LA, USA). The following serum markers were tested with enzyme immunoassay (EIA) kits: total OC (Takara Shuzo Co Ltd., Shiga, Japan); N-telopeptide of type 1 collagen (NTx) (SRL Inc., Tokyo, Japan).

Serum ucOC, serum total OC, and serum NTx levels were measured at 0, 3, 6, and 12 months after the start of ADT.

\section{Measurement of BMD}

Total hip BMD was measured with DXA (GE Prodigy Advance densitometer; Alaka Medical Systems, NY, USA). The coefficient of variation of the measurement was $<1.0 \%$ for the proximal femur. Data for BMD are expressed as $\mathrm{g} / \mathrm{cm}^{2}$. Bone mineral density (BMD) of the total hip was measured at 0,6 and 12 months after ADT.

\section{Statistical analysis}

Statistical analysis was performed by using JMP 9.0 software (SAS Institute Inc.). The Wilcoxon rank-sum non-parametric test was used to determine differences between groups. Correlation between variables was calculated by multiple regression analysis. P values $<0.05$ were considered statistically significant.

\section{Results}

\section{Baseline characteristics of the study patients}

Fifty non-osteoporotic men with prostate cancer who received androgen deprivation therapy (ADT) were enrolled in this observational study. Baseline data are summarized in Table 1. No patients had bone metastases on bone scintigraphy and/or magnetic resonance imaging. Six patients had pelvic lymph node metastases on computed tomography, 11 had extracapsular extension (T3), and 33 had organ-confined (T1/2) disease. The median age, prostate-specific antigen level, and Gleason scores were 74 years, $11.2 \mathrm{ng} / \mathrm{ml}$, and 7 , respectively. The median serum total and free testosterone values at baseline were $389 \mathrm{ng} / \mathrm{dl}$ and $5.50 \mathrm{pg} / \mathrm{ml}$, respectively. Five patients had a serum ucOC level $>4.5 \mathrm{ng} / \mathrm{ml}$ and 3 had a serum NTx level $>16.5$ nmol bone collagen equivalents (BCE)/L.

Changes in serum ucOC, serum OC, ucOC/OC ratio, and serum NTx during the course of ADT (Table 2 and Figures 1a-1c). The average serum ucOC level consistently increased during the course of ADT. The serum levels of ucOC at 6 and 12 months showed statistically higher values than at baseline (Figure 1a). Serum OC also increased after $\mathrm{ADT}$ and showed a statistical difference at 12 months (Figure 1b). Importantly, the ucOC/OC ratio also increased after ADT, and showed a statistical difference at 12 months, possibly indicating an increase in serum ucOC induced by vitamin $\mathrm{K} 2$ deficiency in bone (Figure 1c).

Serum levels of NTx showed a significant increase after 3 months of ADT $(11.9 \pm 2.93 \mathrm{nmol} \mathrm{BCE} / \mathrm{L}$ at baseline vs. $15.7 \pm 5.26 \mathrm{nmol} \mathrm{BCE} / \mathrm{L}$ after 3 months) (Figure 2). The increase in serum NTx occurred earlier than the increase in serum OC. These results suggest that ADT induces high bone turnover and that bone absorption may precede bone formation.

BMD decreased sequentially after the start of ADT, and BMD values at 6 and 12 months $\left(0.94 \pm 0.13\right.$ and $\left.0.91 \pm 0.12 \mathrm{~g} / \mathrm{cm}^{2}\right)$ were significantly $(\mathrm{p}<0.01)$ lower than baseline values (Figure 3$)$.

\begin{tabular}{|l|l|l|l|}
\hline & Mean \pm SD & Median & Range \\
\hline Age (year) & $74 \pm 7.0$ & 74 & $58 \sim 88$ \\
\hline PSA (ng/ml) & $25.7 \pm 36.9$ & 11.2 & $4.1 \sim 163$ \\
\hline Gleason score & $7.3 \pm 1.1$ & 7 & $6 \sim 10$ \\
\hline Total testosterone (ng/dl) & $416 \pm 154$ & 389 & $203 \sim 1060$ \\
\hline Free testosterone (pg/ml) & $5.93 \pm 2.17$ & 5.50 & $1.80 \sim 12.1$ \\
\hline BMD of total hip (g/m²) & $0.95 \pm 0.13$ & 0.95 & $0.74 \sim 1.43$ \\
\hline ucOC (ng/ml) & $2.46 \pm 1.46$ & 2.06 & $0.44 \sim 6.36$ \\
\hline Total OC (ng/ml) & $5.26 \pm 1.86$ & 4.70 & $2.80 \sim 11.0$ \\
\hline Serum NTx (nmolBCE/L) & $11.9 \pm 2.93$ & 11.3 & $6.4 \sim 20.2$ \\
\hline $\begin{array}{l}\text { BCE: Bone Collagen Equivalent; ucOC: Undercarboxylated osteocalcin; NTx: N- } \\
\text { telopeptide; BMD: Bone Mineral Density }\end{array}$ & & \\
\hline
\end{tabular}

Table 1: Baseline characteristics of patients with prostate cancer $(\mathrm{n}=50)$.

\begin{tabular}{|l|l|l|l|l|}
\hline \multirow{2}{*}{} & \multicolumn{3}{|c|}{ ADT } \\
\cline { 2 - 5 } & \multicolumn{1}{|c|}{ Baseline } & 3 months & 6 months & \multicolumn{1}{|c|}{ 1 year } \\
\hline ucOC $(\mathrm{ng} / \mathrm{ml})$ & $\begin{array}{l}2.46 \\
(1.46)\end{array}$ & $2.87(1.83)$ & $3.86(2.28)^{\mathrm{a}), \mathrm{b})}$ & $4.32(1.76)^{\mathrm{a}), \mathrm{b}), \mathrm{c})}$ \\
\hline OC $(\mathrm{ng} / \mathrm{ml})$ & $\begin{array}{l}5.26 \\
(1.86)\end{array}$ & $5.52(1.75)$ & $5.92(1.88)$ & $7.82(2.65)^{\mathrm{a}), \mathrm{b}), \mathrm{c})}$ \\
\hline $\begin{array}{l}\text { \%ucOC } \\
(\mathrm{ucOC} / \mathrm{OC})\end{array}$ & $\begin{array}{l}0.42 \\
(0.18)\end{array}$ & $0.46(0.19)$ & $0.54(0.17)$ & 0.54 \\
\hline $\begin{array}{l}\text { NTx } \\
\text { BCE/L) }\end{array}$ & $\begin{array}{l}11.9(2.93) \\
(\mathrm{nmol})\end{array}$ & $15.7(5.26)^{\mathrm{a})}$ & $16.0(4.01)^{\mathrm{a}), \mathrm{b}), \mathrm{d})}$ & $16.4(4.22)^{\mathrm{a}), \mathrm{b})}$ \\
\hline BMD (g/m²) & $\begin{array}{l}0.95 \\
(0.13)\end{array}$ & - & $0.94(0.13)^{\mathrm{a})}$ & $0.12)^{\mathrm{a}), \mathrm{c})}$ \\
\hline
\end{tabular}

(a) $p<0.01$ vs before ADT; b) $p<0.01$ vs 3 months after ADT; c) $p<0.01$ vs 6 months after ADT; d) $p<0.05$ vs 6 months after ADT

Table 2: Means (SD) of serum undercarboxylated osteocalcin (ucOC), serum osteocalcin (OC), \%ucOC, serum type1 N-telopetide (NTx), and total hip bone mineral density (BMD) before and after androgen deprivation therapy (ADT). 


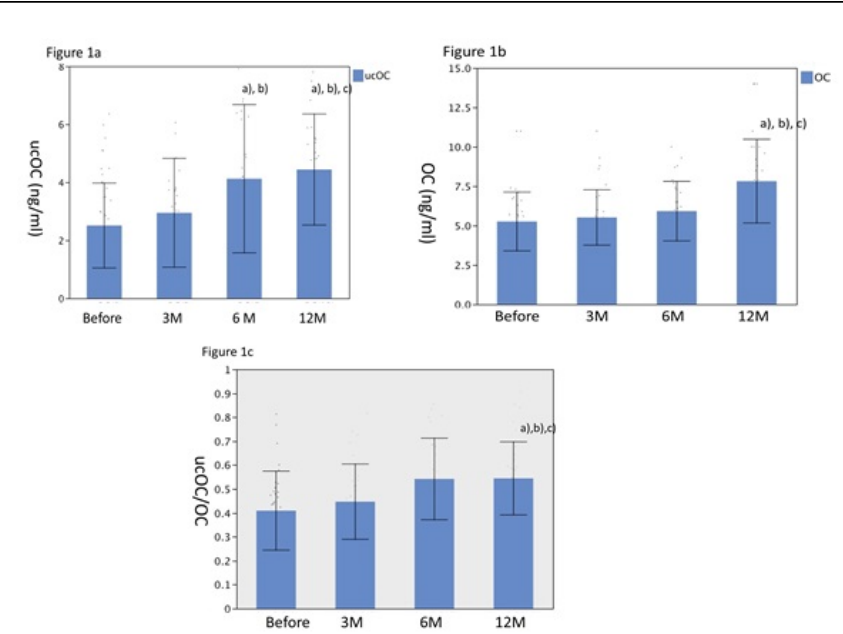

Figure 1: (a) Changes in serum ucOC before and after ADT. The serum levels of ucOC at 6 and 12 months after ADT were significantly higher than at baseline and at 3 months. The serum level of ucOC at 12 months after ADT was significantly higher than at 6 months. (b) Changes in serum OC before and after ADT. The serum level of OC at 12 months after ADT was significantly higher than at baseline, 3 months, and 6 months. (c) Changes in the $\mathrm{ucOC} / \mathrm{OC}$ ratio before and after $\mathrm{ADT}$. The $\mathrm{ucOC} / \mathrm{OC}$ ratio at 12 months after ADT was significantly higher than at baseline, 3 months, and 6 months. a): $p<0.01$ vs. baseline, b): $p<0.01$ vs. 3 months after $A D T, c): p<0.01$ vs. 6 months after $A D T, d): p<0.05$ vs. 6 months after ADT. ${ }^{\star}$ Statistical differences were determined with the Wilcoxon rank-sum test.

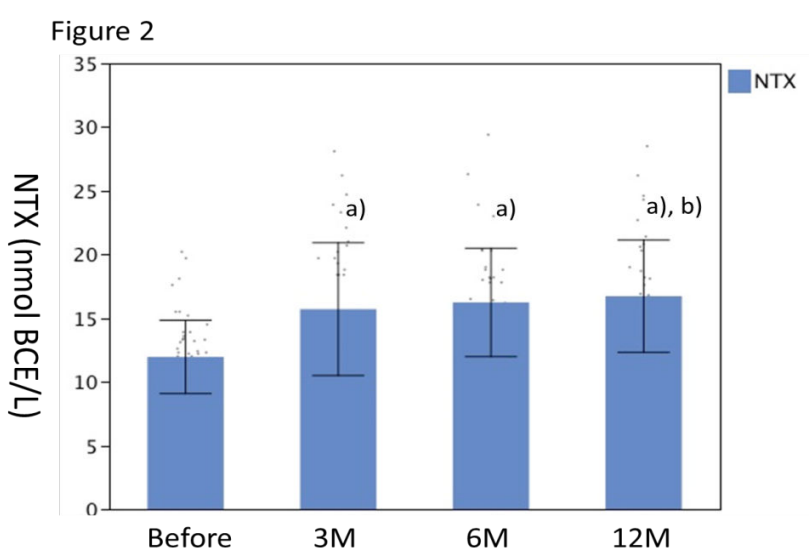

Figure 2: Changes in serum levels of N-telopeptide of type 1 collagen (NTx) before and after ADT. The serum levels of NTx at 3 and 6 months after ADT were significantly higher than at baseline. The serum level of NTx at 12 months after ADT was significantly higher than at baseline and at 3 months after ADT. a): $p<0.01$ vs. baseline b): $p<0.01$ vs. 3 months after ADT. ${ }^{\star}$ Statistical differences were determined with the Wilcoxon rank-sum test.

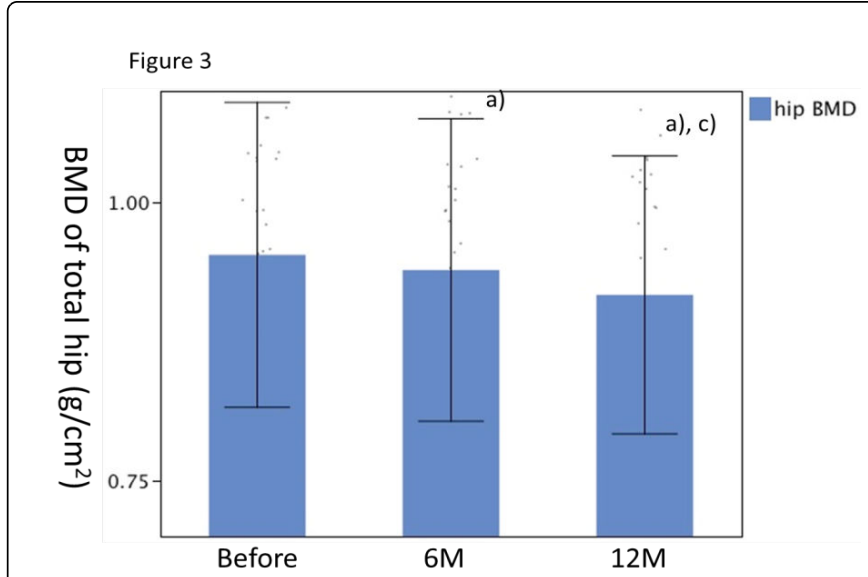

Figure 3: Changes in total hip bone mineral density (BMD) before and after ADT. The BMD at 6 months after ADT was significantly lower at baseline. The BMD at 12 months after ADT was significantly lower than at baseline and at 6 months after ADT. a): $\mathrm{p}<0.01$ vs. baseline, c): $\mathrm{p}<0.01$ vs. 6 months after ADT. ${ }^{\star}$ Statistical differences were determined with the Wilcoxon rank-sum test.

\section{Relationship between ucOC, total OC, NTx, and BMD before and after ADT}

The relationship between serum ucOC, serum OC, serum NTx, and total hip BMD was examined at baseline and at 6 and 12 months after the start of ADT (Table 3). The correlation coefficients between serum ucOC and serum OC were 0.824 at baseline, 0.801 at 6 months, and 0.781 at 12 months. There was a strong correlation during the entire ADT treatment period. Serum ucOC was weakly correlated with both serum NTx and total hip BMD at baseline, but there was no correlation during the ADT treatment period. Serum OC was moderately correlated with serum NTx at baseline and 12 months after the start of ADT, but transiently lost a positive correlation with serum NTx. Serum NTx was not correlated with total hip BMD at baseline or during the entire ADT treatment period.

Association of total and free testosterone with age, ucOC, OC, NTx, and BMD at baseline (Table 4). Serum total testosterone was strongly correlated with free testosterone at baseline $(r=0.554, \mathrm{p}<0.0001)$. Free testosterone was negatively correlated with age $(\mathrm{r}=-0.44, \mathrm{p}=0.0015)$. Total testosterone was positively correlated with $\mathrm{OC}$ and negatively correlated with total hip BMD. 
Citation: Matsushima H (2017) Androgen Deprivation Therapy Induces Vitamin K Loss in Men with Prostate Cancer. Biol Med (Aligarh) 9: 404.

Page 4 of 6

\begin{tabular}{|c|c|c|c|c|c|c|}
\hline Variable & Vs variable & Coefficient & $\mathbf{N}$ & $95 \% \mathrm{Cl}$ & Probability & Time \\
\hline \multirow[t]{3}{*}{$\mathrm{ucOC}$} & \multirow[t]{3}{*}{ OC } & 0.824 & 35 & $0.676,0.907$ & $<0.0001^{*}$ & baseline \\
\hline & & 0.801 & 30 & $0.620,0.901$ & $<0.0001^{*}$ & 6 months \\
\hline & & 0.781 & 33 & $0.598,0.886$ & $<0.0001^{*}$ & 12 months \\
\hline \multirow[t]{3}{*}{ ucOC } & \multirow[t]{3}{*}{ NTX } & 0.329 & 47 & $0.046,0.563$ & $0.0238^{*}$ & baseline \\
\hline & & 0.158 & 39 & $-0.165,0.451$ & 0.3366 & 6 months \\
\hline & & 0.295 & 36 & $-0.036,0.568$ & 0.0804 & 12 months \\
\hline \multirow[t]{3}{*}{ ucOC } & \multirow[t]{3}{*}{ BMD } & -0.323 & 47 & $-0.558,-0.039$ & $0.0267^{*}$ & baseline \\
\hline & & 0.001 & 35 & $-0.332,0.334$ & 0.9956 & 6 months \\
\hline & & -0.100 & 36 & $-0.415,0.235$ & 0.5584 & 12 months \\
\hline \multirow[t]{3}{*}{ OC } & \multirow[t]{3}{*}{ NTx } & 0.397 & 35 & $0.074,0.645$ & $0.0179^{*}$ & baseline \\
\hline & & 0.102 & 30 & $-0.267,0.446$ & 0.5903 & 6 months \\
\hline & & 0.456 & 33 & $0.133,0.691$ & $0.0076^{*}$ & 12 months \\
\hline \multirow[t]{3}{*}{ OC } & \multirow[t]{3}{*}{ BMD } & -0.346 & 35 & $-0.609,-0.014$ & $0.0415^{*}$ & baseline \\
\hline & & 0.246 & 26 & $-0.155,0.578$ & 0.2246 & 6 months \\
\hline & & -0.152 & 33 & $-0.470,0.201$ & 0.3981 & 12 months \\
\hline \multirow[t]{3}{*}{ NTX } & \multirow[t]{3}{*}{ BMD } & -0.267 & 46 & $-0.517,0.024$ & 0.0723 & baseline \\
\hline & & -0.035 & 34 & $-0.369,0.306$ & 0.8408 & 6 months \\
\hline & & -0.189 & 36 & $-0.487,0.148$ & 0.2688 & 12 months \\
\hline
\end{tabular}

Table 3: Correlations between ucOC, OC, NTx, and BMD at baseline and 6 and 12 months after ADT.

\begin{tabular}{|l|l|l|l|l|l|l|}
\hline \multirow{2}{*}{ Variable } & \multicolumn{3}{|c|}{ Total testosterone } & \multicolumn{3}{c|}{ Free testosterone } \\
\cline { 2 - 8 } & \multicolumn{1}{|c|}{ Correlation coefficient } & \multicolumn{1}{|c|}{$\mathbf{9 5 \%}$ Cl } & P value & Correlation coefficient & \multicolumn{1}{c|}{$95 \%$ Cl } & \multicolumn{1}{c|}{ P value } \\
\hline Age & 0.01 & $-0.26,0.29$ & 0.9281 & -0.44 & $-0.64,-0.18$ & 0.0015 \\
\hline ucOC & 0.15 & $-0.13,0.41$ & 0.2822 & 0.19 & $-0.09,0.45$ & 0.1862 \\
\hline OC & 0.40 & $0.08,0.65$ & 0.0147 & 0.27 & $-0.06,0.55$ & 0.1132 \\
\hline NTX & 0.06 & $-0.22,0.34$ & 0.6679 & 0.06 & $-0.423,0.34$ & 0.6836 \\
\hline BMD & -0.28 & $-0.52,-0.00$ & 0.0481 & -0.17 & $-0.44,0.11$ & 0.2394 \\
\hline
\end{tabular}

Table 4: Correlation of total and free testosterone with age, ucOC, OC, NTX, and BMD at baseline.

\section{Discussion}

ADT is a standard treatment for advanced prostate cancer. The adverse effects include loss of libido, hot flashes, osteoporosis, bone fractures, sarcopenia, and increased fat mass [14,15]. Of these, osteoporosis and bone fractures are of particular concern in the management of prostate cancer patients. Rapid bone loss occurs within 6 to 12 months after ADT is initiated [2,16]. Previous studies have shown that men on ADT were $21-37 \%$ more likely to experience a fracture $[3,5,17]$.
Estrogens play an important and perhaps a dominant role in regulating bone loss in elderly men [18], while recent studies have demonstrated that testosterone may also contribute to fracture risk, particularly in the setting of high sex-hormone binding globulin (SHBG) levels [19]. Therefore, serum free testosterone is commonly used as a surrogate for bioactive testosterone. In this study, both total and free serum testosterone were measured at baseline and correlations with age, OC, ucOC, NTx, and BMD were examined. It was found that free testosterone was inversely correlated with age and that total testosterone was correlated with OC. However, it was not 
Page 5 of 6

clear why total testosterone was inversely correlated with BMD and free testosterone was not correlated with BMD. Estradiol should be tested to help clarify these results.

Serum ucOC, a marker of vitamin $\mathrm{K}$ status, is considered to be an independent risk factor for hip fractures [20], and is correlated with age [9] in women. Yasui et al. reported that serum ucOC levels were inversely correlated with serum estradiol levels [21]. They also reported in their longitudinal study that serum ucOC levels and the ucOC/OC ratio increased more rapidly than serum OC levels after bilateral oophorectomy [12]. In the present study, we showed that serum ucOC levels significantly increased at 6 months after ADT was initiated in men, and that serum $\mathrm{OC}$ and the ucOC/OC ratio significantly increased at 12 months. To our knowledge, this is the first report on changes in serum ucOC, serum OC levels, and the ucOC/OC ratio in men before and after ADT. The most important finding in our study is the increase in the ratio of ucOC/OC after ADT, which suggests that vitamin $\mathrm{K}$ is inadequate for conversion of ucOC to carboxylated OC. The mechanism of vitamin K loss in men on ADT is unclear. In experimental models, dietary vitamin $\mathrm{K}$ was shown to ameliorate the LPS-induced reduction in testicular testosterone synthesis [22]. Therefore, it is hypothesized that vitamin $\mathrm{K}$ loss is due to vitamin $\mathrm{K}$ consumption in the testis to inhibit testosterone reduction by ADT.

We also showed that an increase in bone resorption and serum NTx was followed by an increase in bone formation and serum OC. Furthermore, serum ucOC levels were significantly correlated with serum NTx levels at 12 months after the start of ADT.

These findings indicate that the elevations of serum ucOC and OC levels may have been caused by enhanced bone turnover induced by ADT. This is supported by the fact that suppression of bone resorption by bisphosphonates also decreases serum OC $[23,24]$. It is true that bisphosphonates prevent bone loss and reduce the risk of fragile bone fractures, but complete prevention of incident bone fractures has not been achieved. Recently, Shiraki et al. reported that incident fractures were likely to occur in patients with high levels of serum ucOC [25]. It has been shown that vitamin K2 treatment rapidly decreases serum ucOC [26], and has a preventive effect on vertebral fractures [27]. Hirao et al. reported that a combination of alendronate and vitamin K2 treatment increased both osteocalcin carboxylation and BMD in the femoral neck in postmenopausal women with osteoporosis [28]. The efficacy of vitamin K2 treatment in hypogonadal men, particularly those on ADT, is unclear.

\section{Conclusion}

We showed that ADT induced high bone turnover coupled with an increase in the ucOC/OC ratio, reflecting vitamin $\mathrm{K}$ loss in men on ADT. To validate this evidence, a prospective large-scale study is necessary. Further investigation is required to determine how ucOC is affected by osteoclast-targeting therapy or vitamin $\mathrm{K}$ supplementation.

\section{References}

1. Smith MR, McGovern FJ, Zietman AL, Fallon MA, Hayden DL, et al. (2001) Pamidronate to prevent bone loss during androgen-deprivation therapy for prostate cancer. N Engl J Med 345: 948-955.

2. Mittan D, Lee S, Miller E, Perez RC, Basler JW, et al. (2002) Bone loss following hypogonadism in men with prostate cancer treated with $\mathrm{GnRH}$ analogs. J Clin Endocrinol Metab 87: 3656-3661.
3. Shahinian VB, Kuo YF, Freeman JL, Goodwin JS (2005) Risk of fracture after androgen deprivation for prostate cancer. N Engl J Med 352: 154-164.

4. Smith MR (2006) Treatment-related osteoporosis in men with prostate cancer. Clin Cancer Res 12: 6315s-6319s.

5. Smith MR, Boyce SP, Moyneur E, Duh MS, Raut MK, et al. (2006) Risk of clinical fractures after gonadotropin-releasing hormone agonist therapy for prostate cancer. J Urol 175: 136-139.

6. Center JR, Nguyen TV, Schneider D, Sambrook PN, Eisman JA (1999) Mortality after all major types of osteoporotic fracture in men and women: an observational study. Lancet 353: 878-882.

7. Ross PD (1998) Osteoporosis: epidemiology and risk assessment. J Nutr Health Aging 2: 178-183.

8. Sullivan S, Wagner J, Resnick NM, Nelson J, Perera SK, et al. (2011) Vertebral fractures and the misclassification of osteoporosis in men with prostate cancer. J Clin Densitom 14: 348-353.

9. Liu G, Peacock M (1998) Age-related changes in serum undercarboxylated osteocalcin and its relationships with bone density, bone quality, and hip fracture. Calcif Tissue Int 62: 286-289.

10. Szulc P, Arlot M, Chapuy MC, Duboeuf F, Meunier PJ, et al. (1994) Serum undercarboxylated osteocalcin correlates with hip bone mineral density in elderly women. J Bone Miner Res 9: 1591-1595.

11. Yasui T, Uemura H, Umino Y, Yamada M, Kuwahara A, et al. (2006) Undercarboxylated osteocalcin concentration in postmenopausal women receiving hormone therapy daily and on alternate days. Menopause 13: 314-322.

12. Yasui T, Uemura H, Tomita J, Miyatani Y, Yamada M, et al. (2007) Change in serum undercarboxylated osteocalcin concentration in bilaterally oophorectomized women. Maturitas 56: 288-296.

13. Nishimura J, Arai N, Fujimatsu J (2007) Measurement of serum undercarboxylated osteocalcin by electrochemiluminescence immunoassay with "Picolumi ucOC" kit. Igaku to Yakugaku 57: 523-535.

14. Genant HK, Wu CY, van Kuijk C, Nevitt MC (1993) Vertebral fracture assessment using a semiquantitative technique. J Bone Miner Res 8: 1137-1148.

15. Sharifi N, Gulley JL, Dahut WL (2005) Androgen deprivation therapy for prostate cancer. JAMA 294: 238-244.

16. Daniell HW, Dunn SR, Ferguson DW, Lomas G, Niazi Z, et al. (2000) Progressive osteoporosis during androgen deprivation therapy for prostate cancer. J Urol 163: 181-186.

17. Smith MR, Lee WC, Brandman J, Wang Q, Botteman M, et al. (2005) Gonadotropin-releasing hormone agonists and fracture risk: a claimsbased cohort study of men with nonmetastatic prostate cancer. J Clin Oncol 23: 7897-7903.

18. Khosla S (2010) Update in male osteoporosis. J Clin Endocrinol Metab 95: 3-10.

19. Mellstrom D, Vandenput L, Mallmin H, Holmberg AH, Lorentzon M, et al. (2008) Older men with low serum estradiol and high serum SHBG have an increased risk of fractures. J Bone Miner Res 23: 1552-1560.

20. Szulc P, Chapuy MC, Meunier PJ, Delmas PD (1993) Serum undercarboxylated osteocalcin is a marker of the risk of hip fracture in elderly women. J Clin Invest 91: 1769-1774.

21. Yasui T, Uemura H, Tomita J, Miyatani Y, Yamada M, et al. (2006) Association of serum undercarboxylated osteocalcin with serum estradiol in pre-, peri- and early post-menopausal women. J Endocrinol Invest 29: 913-918.

22. Takumi N, Shirakawa H, Ohsaki Y, Ito A, Watanabe T, et al. (2011) Dietary vitamin $\mathrm{K}$ alleviates the reduction in testosterone production induced by lipopolysaccharide administration in rat testis. Food Funct 2: 406-411.

23. Shiraki M, Kushida K, Fukunaga M, Kishimoto H, Kaneda K, et al. (1998) A placebo-controlled, single-blind study to determine the appropriate alendronate dosage in postmenopausal Japanese patients with osteoporosis. The Alendronate Research Group. Endocr J 45: 191-201. 
Citation: Matsushima H (2017) Androgen Deprivation Therapy Induces Vitamin K Loss in Men with Prostate Cancer. Biol Med (Aligarh) 9: 404. doi:10.4172/0974-8369.1000404

Page 6 of 6

24. Tucci JR, Tonino RP, Emkey RD, Peverly CA, Kher U, et al. (1996) Effect of three years of oral alendronate treatment in postmenopausal women with osteoporosis. Am J Med 101: 488-501.

25. Shiraki M, Yamazaki Y, Shiraki Y, Hosoi T, Tsugawa N, et al. (2010) High level of serum undercarboxylated osteocalcin in patients with incident fractures during bisphosphonate treatment. J Bone Miner Metab 28: 578-584.

26. Miki T, Nakatsuka K, Naka H, Kitatani K, Saito S, et al. (2003) Vitamin $\mathrm{K}(2)$ (menaquinone 4 ) reduces serum undercarboxylated osteocalcin level as early as 2 weeks in elderly women with established osteoporosis. J Bone Miner Metab 21: 161-165.

27. Shiraki M, Shiraki Y, Aoki C, Miura M (2000) Vitamin K2 (menatetrenone) effectively prevents fractures and sustains lumbar bone mineral density in osteoporosis. J Bone Miner Res 15: 515-521.

28. Hirao M, Hashimoto J, Ando W, Ono T, Yoshikawa H (2008) Response of serum carboxylated and undercarboxylated osteocalcin to alendronate monotherapy and combined therapy with vitamin $\mathrm{K} 2$ in postmenopausal women. J Bone Miner Metab 26: 260-264. 